Bol. Acad. peru. leng. 69. 2021 (403-409)

\title{
Incorporación de la doctora Eliana Gonzales Cruz a la Academia Peruana de la Lengua
}

\author{
Alberto Varillas Montenegro \\ Academia Peruana de la Lengua, Lima, Perú \\ varillas.alberto@gmail.com \\ https://orcid.org/0000-0003-4056-5658
}

Recibido: 01/12/2020 Aceptado: 27/02/2021 Publicado: 30/06/2021

Señor presidente de la Academia Peruana de la Lengua, Señores miembros de la Academia, Señoras y señores:

Fue por cierto una excelente decisión de la Asamblea General de la Academia haber aprobado la incorporación a su seno, como Miembro de Número, de la doctora Eliana Gonzales Cruz. Y lo digo porque siento que su presencia entre sus ahora colegas viene a llenar tres vacíos que se percibían desde tiempo atrás: era importante reforzar el área de lingüística, lo mismo debo decir sobre la presencia femenina entre los miembros y, pese a que se desempeña en la sede limeña, proviene de una importante universidad de fuera de la capital donde se ha desempeñado como Coordinadora 
del Área de Lengua y Literatura y ha sido Directora de Investigación y Publicaciones. Y quizás a esos tres asuntos convenga referirnos hoy, día en que la Academia Peruana de la Lengua anuncia su incorporación.

Decía a mediados del siglo pasado un ilustre miembro de nuestra Academia, el doctor Raúl Porras Barrenechea, que «el lenguaje y el mito son las primitivas cristalizaciones del alma primitiva de un pueblo», y teniendo presente a Max Müller (1823-1900) —el filólogo alemán promotor de los estudios comparados de filosofía, mitología y lenguaje — insistía en que lenguaje y mito debían ser tratados como hermanos gemelos. Al estudiar la importancia de ambos conceptos en la formación de la tradición y la historia en el Perú, recuerda Porras cómo, al llegar a estas tierras, los primeros historiadores europeos se maravillaron al reparar en el elevado número de lenguas que se hablaban entre nosotros. La situación interesó a un buen número de los recién llegados pobladores del flamante virreinato, que pronto comenzaron a estudiar las nuevas lenguas que iban encontrando - las cuales llegaban a 700, según estimó el P. Acosta—. Entre ellos debe destacarse al dominico Fray Domingo de Santo Tomás que pronto, en 1560, publicó su Gramática o Arte General de la lengua general de los indios de los Reynos del Perú y, además, su Lexicón o Vocabulario de la lengua general del Perú llamada quichua, con lo que se constituyó en el fundador de los estudios de lingüística en el Perú. La labor precursora de Fray Domingo de Santo Tomás tuvo acogida y pronto encontró seguidores que prepararon gramáticas o vocabularios que apoyaban a la autoridad de aquellos tiempos en sus esfuerzos por poderse comunicar y dictar órdenes tanto en el ámbito administrativo cuanto en el catequético. Y con esta vocación por el estudio de la lengua, nos hallamos nosotros entre sus seguidores, pues hoy podemos dar testimonio de nuestro respeto por el primitivo lema fundacional de la Real Academia que era «Limpia, fija y da esplendor» a la lengua que hablamos. Por lo tanto, debe quedar establecido que la preocupación por estudiar la lengua se remonta a muchos siglos atrás y que de lo dicho no debe suponerse que ni la Lingüística ni la Lexicografía han estado desatendidas en el Perú ni por los peruanos ni, por supuesto, por nuestra Academia.

Fue precisamente un compatriota nuestro, el lexicógrafo piurano Diego de Villegas y Quevedo — cuya vida cubre la primera mitad del 
https://doi.org/10.46744/bapl.202101.017

siglo XVIII (1696-1751)—, quien se encargó, en la Corte española ya dominada por los Borbones, de la preparación de una parte del primer Diccionario de Autoridades, que está próximo a cumplir 300 años, pues fue impreso en 6 volúmenes entre 1726 y 1739. Don Diego cumplió con el encargo y entregó inicialmente las cédulas correspondientes a la sílaba Ma (1060 papeletas) y luego redactó íntegra la parte correspondiente a la letra $M$, que cubre 394 columnas de la primera edición. Y entre los cuidadosos aportes de don Diego encontramos las primeras versiones de dos voces que hoy nos parecen familiares: mazamorra y manjarblanco.

Los tres siglos que nos alejan hoy del primitivo Diccionario de Autoridades no determinaron una separación del Perú de la Real Academia Española, pues varios limeños ocuparon en ella los más altos cargos directivos. Cabe recordar a los Directores perpetuos José Miguel de Carvajal y Vargas Manrique de Lara, Duque de San Carlos, elegido en 1814; y a Juan de la Pezuela y Ceballos, marqués de la Pezuela y Conde de Cheste, hijo limeño del virrey Joaquín de la Pezuela, quien desempeñó el mismo cargo durante 31 años, entre 1875 y 1906. También es grato considerar, en tiempos más cercanos, a Mario Vargas Llosa, miembro de número de nuestra Academia desde 1975 y elegido en la misma categoría por la española en 1996.

La preocupación por el estudio del lenguaje peruano tuvo también un importantísimo reconocimiento republicano decimonónico. Hagamos alusión solo a dos de los fundadores de la Academia Correspondiente de la Real Española en el Perú, pues tal fue el nombre con el que se fundó hace 130 años la Academia Peruana de la Lengua. El primero es Juan de Arona (1839-1895), quien publicó en 1861 su Galería de novedades filológicas, que luego amplió y ofreció al público en 1883 como Diccionario de Peruanismos. El segundo es don Ricardo Palma (18331919), el gran promotor de nuestra Academia, autor de sus Neologismos y americanismos (1896) y Papeletas lexicográficas (1903), quien log ró que la futura Academia Peruana de la Lengua se autorecesara durante casi 25 años, hasta 1917, en virtud de las airadas discusiones que tuvo en Madrid entre 1892 y 1893. 
Y no es posible terminar este rápido recuento sin tener presentes los nombres de dos miembros de número de nuestra Academia: Miguel Ángel Ugarte Chamorro (1910-1990), la importancia de cuyos Arequipeñismos (1942) y Diccionario ortográfico... (1952) son proverbiales, y Martha Hildebrandt (1925), que lamentablemente hoy no ha podido acompañarnos, cuyos estudios sobre El español en Piura (1949), La lengua de Bolivar (1961) y especialmente su Peruanismos (1969 y 1994) constituyen aportes de carácter lingüístico de extraordinaria jerarquía.

Y para concluir el desarrollo de este tópico es necesario recordar los últimos dos diccionarios de peruanismos: el que publicó en 1990 Juan Álvarez Vita y, en especial, el de Julio Calvo Pérez, quien encabezó a un grupo particularmente selecto de lexicógrafos para preparar DiPerú, trabajo notable por el cual tanto se interesó don Alberto Benavides de la Quintana, presidente del Directorio de Buenaventura S.A. y miembro honorario de nuestra Academia.

* * * *

Decíamos al iniciar esta presentación que merecía destacarse la incorporación de una segunda mujer al grupo de miembros de número de la Academia Peruana de la Lengua, y bien vale recordar brevemente la forma en que este punto se trató en el pasado. En 1784, cuando la Real Academia Española acababa de cumplir 70 años de vida, ingresa a ella, como miembro honorario, la doctora María Isidora de Guzmán y de la Cerda, la primera mujer que había optado dicho grado en la Universidad de Alcalá. Hoy se cree que la decisión de incorporarla puede haberse generado por algún tipo de presión política, pues doña Isidora no regresó a la Academia. Y en el caso español, por acuerdo adoptado a raíz de la posible admisión de la escritora cubana Gertrudis Gómez de Avellaneda (Camaguey, 1814-1873), quien en 1853 había estrenado con éxito en Madrid cinco obras dramáticas, algunos desacuerdos debe haber habido en los debates de la Real Academia Española, pues no se dio pase al expediente y tiempo después la institución acordó que en el futuro no aceptaría la incorporación de damas. 
https://doi.org/10.46744/bapl.202101.017

Pero felizmente la vida no está hecha por acuerdos, sino formada por realidades, y 125 años después, en 1978, la Real Academia Española incorporó como primer miembro de número de sexo femenino a Carmen Conde, destacada ensayista y esencialmente creadora, pues fue poetisa, narradora y dramaturga. Carmen Conde y su esposo, Antonio Oliver Belmás, fueron integrantes de la conocida Generación del '27, y don Antonio fue un destacado peruanista autor de un importante estudio sobre nuestro José Gálvez, quien en vida también fuera miembro de la Academia Peruana de la Lengua. Lo interesante de este hecho es que tres años antes de la admisión de Carmen Conde a la Real Academia Española, la Academia Peruana de la Lengua ya había recibido entre sus miembros de número a una mujer, y hoy figuran damas en todas las Academias latinoamericanas y en algún caso, las presiden. Por ello, cabe destacar que, con la incorporación a la cual se da paso hoy en este acto académico - pues para estos efectos una Asamblea General como ésta es un acto académico - las dos únicas mujeres que forman parte de la Academia Peruana de la Lengua como miembros de número tienen una marcada vocación por la Lingüística y la Lexicografía: las doctoras Martha Hildebrandt Pérez Treviño y Eliana Gonzales Cruz.

Se remonta a muchos años atrás la participación de mujeres en la literatura peruana. Desde que «una señora principal de este Reyno, muy versada en la lengua toscana y portuguesa» dirigiera a Diego Mexía de Fernangil en 1608 su Discurso en loor de la poesía y desde que Amarilis invocara a Lope de Vega en 1621, en su conocida Epístola a Belardo, muchas han sido las escritoras peruanas dedicadas con ahínco al quehacer literario y su vocación ha sido reconocida sin limitación alguna. Ya en los años de la república, los nombres de Mercedes Cabello de Carbonera, Clorinda Matto de Turner, Carolina Freire de Jaimes, Rosa Mercedes Riglos de Orbegoso, Manuela Villarán de Plasencia, Angélica Palma y otras mostraron una clara vocación literaria y, aunque prefirieron ejercerla más en el ámbito de la poesía y algo menos en el del periodismo y del ensayo, con alguna que otra excepción casual, las damas no han dado muestra de especial interés en los temas lingüísticos. Lo que le confiere a esta incorporación un relieve especial, pues seguramente favorecerá el interés femenino por estos temas. 
Pero el último punto que destaqué al iniciar esta presentación está relacionado con el hecho de que la doctora Gonzales es docente en la Universidad de Piura, así fuera en el campus de Lima. Lo ocurrido, que quizás no ha sido percibido por la totalidad de los académicos vinculados a su nombramiento e incorporación, implica que, en cierto modo, la Academia ha optado por una posición favorable a la descentralización de sus actividades y ha incrementado sus esfuerzos por ampliar sus contactos con personas y grupos culturales ubicados fuera de la gran Lima, tal como la había iniciado con un congreso llevado a cabo en Piura y con la serie de publicaciones producidas conjuntamente con la iqueña Biblioteca Abraham Valdelomar, mediante convenio que debía tratarse de reforzar. Lo cual debe considerarse positivo.

* $\quad * \quad *$

Pero reparo que es posible que haya destacado más la importancia del nombramiento de Eliana Gonzales sin haberme detenido en sus valores personales. No quiero insistir en sus estudios y grados, pues referencias a su doctorado en Lingüística Hispánica por la Universidad de Navarra ha sido aludido un sinnúmero de veces en este acto académico. Ya desde comienzo del presente siglo apareció con sus manuales de Lengua castellana I (2003) y Lengua castellana II (2003, reeditado en el 2011) y su Literatura peruana para el Sistema Semipresencial (SEAD) de la Facultad de Ciencias de la Educación de la Universidad de Piura; colaboró durante largo tiempo en la preparación de DiPerú, el más reciente Diccionario de Peruanismos, pero hasta hoy su trabajo más importante es el estudio antroponímico en tres narradores peruanos: Bryce, Scorza y Ribeyro, titulado La denominación en la caracterización de personajes. Y dándole continuidad a su vocación, aparece declarando su pasión por los diccionarios y junto con otros integrantes del blog Castellano actual, tiene el sueño de preparar un Diccionario de dudas, que hoy no existe en el Perú.

* $\quad * \quad *$

Por todo lo dicho - y seguramente por mil razones más- resulta importante la incorporación de la doctora Eliana Gonzales Cruz a la 
https://doi.org/10.46744/bapl.202101.017

Academia Peruana de la Lengua. No solo se trata de una persona de grandes calidades personales, a las cuales quizás debí haberme referido más extensamente, sino por su calidad de lingüista amante de la lexicografía, por su condición de mujer y su desempeño laboral dentro de una universidad alejada de Lima dan a su incorporación características muy particulares. Sin duda los académicos interesados en el área de lingüística van a encontrar en ella a una colega dispuesta a aportar los conocimientos actualizados que posee en el ámbito de la lexicografía, para todos será una satisfacción compartir su versación en la literatura peruana, y, por qué no decirlo, su jovialidad.

Por ello, en momentos de su incorporación como miembro de número de la Academia Peruana de la Lengua, al haber sido designado por el Consejo Directivo para el discurso de recepción, tal como lo establece el artículo décimo cuarto de nuestros Estatutos, puedo decirle con mucho gusto ibienvenida, académica Eliana Gonzales Cruz! 